\title{
Assessing impact of oral diseases on oral health related quality of life of institutionalized elderly using OHIP-14 in Bengaluru: A cross sectional study
}

\author{
${ }^{1}$ Krishnappa Pushpanjali, ${ }^{2}$ Malu Mohan, ${ }^{3}$ Piddennavar Renuka, \\ ${ }^{1}$ Proffesor and Head, Dept of Public Health Dentistry, MS Ramaiah Dental College and Hospital Bengaluru, \\ Karnataka, India \\ ${ }^{2}$ Senior Lecturer, Dept of Public Health Dentistry, Azeezia Dental College and Hospital Kollam, Kerala, \\ India \\ ${ }^{3}$ Senior Lecturer, Dept of Public Health Dentistry, ACP Dental College and Hospital Dhule, Maharastra, India
}

\begin{abstract}
The proportion of older people is growing faster than that of any other age group. The interrelationship between oral health and general health is particularly pronounced among older people. Poor oral health exerts a negative impact on the quality of life of geriatric population. There is no sound database regarding the oral disease burden and treatment needs of the elderly in India and the extent to which oral diseases impact the general health and quality of lives of the Indian elderly. A survey conducted among 218 subjects above 60 years of age residing in seven old age homes across Bengaluru city to assess the impact of oral diseases on oral health related quality of life using OHIP-14 questionnaire tool. Independent t-test revealed that, presence or absence of grossly decayed teeth produced significant differences in the physical pain, physical discomfort and handicap domains while edentulism (partial or complete) produced significant impact in the psychological disability domain of elderly subjects. Females experienced greater impact of oral diseases than males in all the domains of OHIP. Oral health status of the institutionalized geriatric population of Bengaluru, India is poor, with edentulism, periodontitis and under utilization being major concerns. The impact of oral diseases on the lives of elderly is relatively lower and disproportionate compared to the disease burden among the subjects.
\end{abstract}

Key words: Elderly, OHIP-14, Oral Health Related quality of Life, Impact of oral diseases.

\section{Introduction}

The world is facing a demographic revolution. There is a dramatic increase in the geriatric population in many developing and developed countries. The proportion of older people is growing faster than that of any other age group. By 2050, the number of elderly is expected to rise to 2 billion, $80 \%$ of whom living in developing countries. This poses tremendous challenges to health and social policy planners, particularly because disease patterns will shift concurrently $([1,2])$. Globally, major oral diseases reported amongst older people have been high levels of tooth loss, dental caries experience, and increased prevalence of periodontal disease, xerostomia and oral pre cancer/cancer. The interrelationship between oral health and general health is particularly pronounced among older people. Oral diseases compromise chewing and eating abilities, thereby affecting the nutritional status in the elderly. Similarly, systemic diseases and/or the adverse side effects of their treatments can lead to increased risk of oral diseases, xerostomia, and altered taste sensation. Poor oral health exerts a negative impact on the quality of life of geriatric population ([3-5]).

India, also, is in a state of demographic transition with a geriatric population of about 80 million, which constitutes $7.2 \%$ of the total population. The prevalence of common dental diseases such as periodontal diseases, dental caries and oral cancer increases with age due to long term accumulation of risk factors like poor oral hygiene and tobacco consumption. The problem of edentulism is highly prevalent among the elderly from the lower socioeconomic groups which is compounded by meager prosthodontic rehabilitation facilities ([6]). Poor accessibility to oral healthcare facilities and uneven distribution of dental expertise are among the major barriers to providing oral health care to the elderly in India. The elderly living alone or in institutions simply have no provision for oral healthcare. This is partly due to the fact that we have no sound database regarding the oral disease burden and treatment needs of the elderly in India ([5)]. In addition, the extent to which oral diseases impact the general health and quality of lives of the Indian elderly have not been extensively studied.

\section{Objective}

This cross-sectional study was conducted among the institutionalized elderly in Bengaluru to assess the impact that oral diseases have on their daily activities and quality of life. 


\section{Materials and Methods}

A survey was conducted among 218 subjects above 60 years of age residing in seven old age homes across Bengaluru city from September $26^{\text {th }}$ to October $2^{\text {nd }}, 2010$. A pilot study was conducted among the residents of two old age homes and the prevalence of edentulism was obtained (13\%). Based on this the sample size of the final study was estimated to be 180 at $95 \%$ confidence interval, with a precision of $5 \%$. A simple random one-stage cluster sample design was employed to select the seven old age homes from among the 75 old age homes across five zones of the city in which all the elderly in each old age home were to be included in the study. Among them, severely debilitated and hearing and/or speech impaired inmates were excluded. Subjects who lacked the cognitive ability required to comprehend and cooperate with the study protocol were also excluded.

Permission was sought from the authorities of the various old age homes prior to the study. Written informed consent was obtained from individual subjects prior to the study. Ethical clearance for the research project was obtained from the Institutional Review Board for Human Ethics, M.S.Ramaiah Dental College \& Hospital, Bengaluru. Face to face, semi-structured interview with a specially designed proforma was used to collect information regarding socio- demographic factors and the oral hygiene practices of the participants. The interview also included assessment of the impact of oral diseases on the daily living and quality of life of the participants using the socio-dental indicator Oral Health Impact Profile ([7]).

The OHIP-14 consists of a form containing 14 questions addressing the dimensions based on the theoretical and conceptual model of oral health formulated by Locker. Functional limitation, physical pain, psychologic discomfort, physical disability, psychologic disability, social disability, and handicap are the seven domains in the tool. Each of the seven subscales has two questions graded on a five-point Likert scale. The tool was translated to the local language Kannada by a panel of linguistic experts. Basic oral health survey was used to assess the oral health status of the subjects ([8]). The clinical examinations were conducted under favorable lighting conditions at the old age homes using mouth mirror and CPI probe. Two investigators who were subjected to prior training and calibration in recording the Basic Oral Health survey proforma performed the examination while two other investigators proficient in the local language (Kannada) interviewed the study subjects. The investigators were calibrated until they achieved an acceptable level of intra and inter examiner reliability $(\kappa \geq 0.8)$. The general health of the participants was reviewed by the medical team that accompanied the investigators to the old age homes. The medical records of the inmates were also examined to obtain information regarding the major systemic conditions that affected them and the treatment provided.

\section{Statistical Analysis}

Data obtained were statistically analyzed using SPSS (Statistical Programme for Social Sciences) version 18. Chi-square test was employed to find the association between the socio demographic variables and oral health status and the impact of oral diseases on the quality of lives of the institutionalized elderly. Unpaired test and one way ANOVA was employed to find statistically significant differences in domain wise impact of OHIP, between groups according to the presence or absence of dental diseases, remaining number of teeth, gender and utilization.

\section{Results}

A total of 258 elderly were institutionalized in the seven old age homes, but 40 of them had to be excluded due to severe debilitation, speech and hearing defects and cognitive impairment. Thus the total number of subjects who participated in the study was 218. All the participants responded positively and consented for the interview and clinical examination. Mean age of the participants of the survey was 71.89 years with an almost equal gender distribution. Majority of the subjects were financially dependent and they were sponsored by the institutions with support from Non Governmental Organizations and charitable associations. A small percentage (19\%) of them could support themselves since they received pensions. (Table: 1)

Hypertension, diabetes mellitus and a combination of both were the major systemic illnesses affecting the participants. Tooth brush and tooth paste was found to be the primary mode of oral hygiene maintenance while majority of the participants brushed only once a day $(70 \%)$. Though complete $(20.6 \%)$ and partial (73.4\%) edentulism were prevalent among the subjects, only $26.6 \%$ of these subjects wore dentures. More than half of the subjects suffered from chronic generalized periodontitis $(52.8 \%)$ and it was found to be more common among the males. The other major problems found among the elderly were dental caries (coronal caries, 30.8\%), multiple unrestorable teeth (grossly decayed and root stumps, 55.5\%) and cervical abrasion (11.9\%). The utilization of oral health care services by the study population was poor with $64.7 \%$ having never visited a dental professional in their life time.

Females were found to experience a greater impact of oral diseases than males (14.28 \pm 7.95$)$ which was statistically significant (Figure 1). On the whole the elderly subjects experienced a low impact of oral 
diseases on the quality of their lives as indicated by the low mean OHIP score $(11.9 \pm 6.5)$. Among the seven domains of OHIP, the greatest impact was on physical pain (painful aching, discomfort while eating) followed by functional limitation (speech and taste). The impact of oral diseases on the other domains of OHIP has been negligible among the study population (Fig: 2). Chi square test was employed to find the association between all the variables under study and the impact according to OHIP scale. The scores of OHIP were grouped based on the impact. Patients with scores of 0 to 2 comprised the group with the lowest impact scores (when their answer for questions scored lower than 2) and those with scores of 3 and 4 comprised the group with the highest impact scores (when answers were score 3 or 4) ([9]). Gender, financial status, and number of remaining teeth were found to have an association with the OHIP scores (Table 2).

According to independent t-test, it was found that presence or absence of grossly decayed teeth produced significant differences in the physical pain, physical discomfort and handicap domains while edentulism (partial or complete) produced significant impact in the psychological disability domain of elderly subjects (Table 3 ).

It was also found that major oral diseases like dental caries (early cavitated lesions and grossly decayed teeth) and chronic generalized periodontitis did not produce a significant impact on the domains of OHIP in the elderly (Table 4). Females were found to have a greater impact on all the domains of OHIP when compared to males and this finding was statistically significant. There was significant impact on the quality of life in the social disability and handicap domains among subjects who did not visit the dental professional even once in their life time (Table 5). One way ANOVA was performed to find the domain wise differences between and within groups according to the number of remaining teeth and it was found that being edentulous or having lesser than 20 functional teeth created a significant impact on the functional limitation and physical discomfort domains (Table 6).

\section{Figures and tables}

Table:1 Distribution of socio demographic variables

\begin{tabular}{|c|c|c|c|}
\hline \multicolumn{2}{|c|}{ Variable } & Number & Percentage \\
\hline \multirow{3}{*}{$\frac{\text { Age }}{\text { distribution: }}$} & $60-70$ & 91 & $41.7 \%$ \\
\hline & $70-80$ & 84 & $38.6 \%$ \\
\hline & $>80$ & 43 & $19.7 \%$ \\
\hline \multirow[t]{2}{*}{ Gender: } & Males & 108 & $49.5 \%$ \\
\hline & Females & 110 & $50.5 \%$ \\
\hline \multirow{4}{*}{$\frac{\text { Marital }}{\text { Status: }}$} & Unmarried & 30 & $13.8 \%$ \\
\hline & Living with & 89 & $40.8 \%$ \\
\hline & spouse & & \\
\hline & $\begin{array}{l}\text { Separated/ } \\
\text { widowed }\end{array}$ & 99 & $45.4 \%$ \\
\hline \multirow{2}{*}{$\frac{\text { Financial }}{\underline{\text { Status }}}$} & Sponsored & 175 & $80.2 \%$ \\
\hline & $\begin{array}{c}\text { Self } \\
\text { supported }\end{array}$ & 43 & $19.8 \%$ \\
\hline
\end{tabular}

Table 2: Association between gender, financial status \& number of remaining teeth with OHIP score

\begin{tabular}{|c|c|c|c|c|}
\hline \multicolumn{2}{|c|}{ Variables } & $\begin{array}{c}\text { Low impact } \\
\mathrm{n}=193\end{array}$ & $\begin{array}{c}\text { High impact } \\
\mathrm{n}=25\end{array}$ & Significance \\
\hline Gender & Males & $106(54.9 \%)$ & $2(8 \%)$ & \\
& Females & $87(45.1 \%)$ & $23(92 \%)$ & $\mathbf{. 0 0 0}$ \\
\hline Financial status & Sponsored & $151(78.2 \%)$ & $24(96 \%)$ & \\
& Self supported & $42(21.8 \%)$ & $1(4 \%)$ & $\mathbf{0 . 0 2 3}$ \\
\hline Number of & $\leq 19$ & $98(50.7 \%)$ & $20(80 \%)$ & $\mathbf{. 0 0 0}$ \\
remaining teeth & $>19$ & $95(49.3 \%)$ & $5(20 \%)$ & \\
& & & & \\
\end{tabular}

Table 3: Domain wise mean OHIP scores according to presence or absence of edentulism and grossly decayed teeth

\begin{tabular}{|c|c|c|c|c|c|c|c|c|}
\hline \multirow[t]{3}{*}{ Domains } & \multicolumn{4}{|c|}{ Edentulism } & \multicolumn{4}{|c|}{ Grossly decayed teeth } \\
\hline & \multicolumn{2}{|c|}{ Mean \pm SD } & \multirow[t]{2}{*}{$\mathbf{t}$} & \multirow[t]{2}{*}{ Sig } & \multicolumn{2}{|c|}{ Mean \pm SD } & \multirow[t]{2}{*}{$\mathbf{t}$} & \multirow{2}{*}{$\begin{array}{c}\text { Signifi } \\
\text { cance }\end{array}$} \\
\hline & + & - & & & + & - & & \\
\hline $\begin{array}{c}\text { Functional } \\
\text { limitation }\end{array}$ & $1.8 \pm 1.79$ & $1.87 \pm 1.9$ & 0.250 & 0.803 & $2.13 \pm 2.01$ & $1.79 \pm 1.85$ & $\begin{array}{c}- \\
0.990 \\
\end{array}$ & 0.323 \\
\hline Physical pain & $2.42 \pm 1.78$ & $2.82 \pm 2.04$ & 1.192 & 0.235 & $3.39 \pm 1.95$ & $2.60 \pm 1.98$ & - & 0.028 \\
\hline
\end{tabular}


Assessing impact of oral diseases on oral health related quality of life of institutionalized elderly

\begin{tabular}{|c|c|c|c|c|c|c|c|c|}
\hline & & & & & & & 2.218 & \\
\hline $\begin{array}{c}\text { Physical } \\
\text { discomfort }\end{array}$ & $1.11 \pm 1.49$ & $1.54 \pm 1.97$ & 1.608 & 0.111 & $2.02 \pm 1.85$ & $1.34 \pm 1.88$ & - & $\mathbf{0 . 0 4 2}$ \\
\hline $\begin{array}{c}\text { Physical } \\
\text { disability }\end{array}$ & $1.57 \pm 1.72$ & $2.04 \pm 2.12$ & 1.363 & 0.174 & $2.44 \pm 2.1$ & $1.85 \pm 2.03$ & - & 0.107 \\
\hline $\begin{array}{c}\text { Psychological } \\
\text { disability }\end{array}$ & $0.73 \pm 1.33$ & $1.2 \pm 1.69$ & 2.000 & $\mathbf{0 . 0 4 9}$ & $1.5 \pm 1.87$ & $1.02 \pm 1.57$ & - & 0.107 \\
\hline $\begin{array}{c}\text { Social } \\
\text { disability }\end{array}$ & $0.77 \pm 1.39$ & $1.15 \pm 1.7$ & 1.354 & 0.177 & $1.39 \pm 1.8$ & $1.01 \pm 1.61$ & - & 0.194 \\
\hline Handicap & $0.8 \pm 1.47$ & $1.08 \pm 1.68$ & 1.021 & 0.308 & $1.57 \pm 1.95$ & $0.91 \pm 1.55$ & - & $\mathbf{0 . 0 2 3}$ \\
\hline
\end{tabular}

Table 4: Domain wise mean OHIP scores according to dental caries and chronic generalized periodontitis

\begin{tabular}{|c|c|c|c|c|c|c|c|c|}
\hline \multirow[t]{3}{*}{ Domains } & \multicolumn{4}{|c|}{ Dental caries } & \multicolumn{4}{|c|}{ Chronic Generalized Periodontitis } \\
\hline & \multicolumn{2}{|c|}{ Mean \pm SD } & \multirow[t]{2}{*}{$\mathbf{t}$} & \multirow[t]{2}{*}{ Sig } & \multicolumn{2}{|c|}{ Mean \pm SD } & \multirow[t]{2}{*}{$\mathbf{t}$} & \multirow{2}{*}{$\begin{array}{l}\text { Signif } \\
\text { icanc } \\
\text { e }\end{array}$} \\
\hline & + & - & & & + & - & & \\
\hline $\begin{array}{l}\text { Functional } \\
\text { limitation }\end{array}$ & $1.54 \pm 1.73$ & $1.98 \pm 1.92$ & 1.574 & 0.117 & $1.73 \pm 1.76$ & $2 \pm 1.99$ & 1.096 & 0.274 \\
\hline Physical pain & $2.67 \pm 2.08$ & $2.76 \pm 1.98$ & 0.298 & 0.766 & $1.23 \pm 1.74$ & $1.69 \pm 2.02$ & 1.819 & 0.70 \\
\hline $\begin{array}{l}\text { Physical } \\
\text { discomfort }\end{array}$ & $1.51 \pm 1.83$ & $1.39 \pm 1.89$ & -0.452 & 0.652 & $2.75 \pm 2.08$ & $2.7 \pm 1.71$ & -0.14 & 0.889 \\
\hline $\begin{array}{l}\text { Physical } \\
\text { disability }\end{array}$ & $2.03 \pm 2.15$ & $1.89 \pm 2.01$ & -0.447 & 0.655 & $1.86 \pm 2.13$ & $2.04 \pm 1.97$ & 0.672 & 0.503 \\
\hline $\begin{array}{c}\text { Psychological } \\
\text { disability }\end{array}$ & $1.04 \pm 1.58$ & $1.10 \pm 1.63$ & 0.244 & 0.807 & $0.93 \pm 1.4$ & $1.31 \pm 1.84$ & 1.723 & 0.086 \\
\hline $\begin{array}{c}\text { Social } \\
\text { disability }\end{array}$ & $1.01 \pm 1.79$ & $1.05 \pm 1.56$ & 0.153 & 0.879 & $0.89 \pm 1.47$ & $1.27 \pm 1.8$ & 1.691 & 0.092 \\
\hline Handicap & $1.06 \pm 1.84$ & $0.95 \pm 1.52$ & -0.416 & 0.653 & $0.86 \pm 1.51$ & $1.19 \pm 1.76$ & 1.459 & 0.146 \\
\hline
\end{tabular}

Table 5: Domain wise mean OHIP scores according to gender and utilization of oral health services

\begin{tabular}{|c|c|c|c|c|c|c|c|c|}
\hline \multirow[t]{3}{*}{ Domains } & \multicolumn{4}{|c|}{ Gender } & \multicolumn{4}{|c|}{ Utilization } \\
\hline & \multicolumn{2}{|c|}{ Mean \pm SD } & \multirow[t]{2}{*}{$\mathbf{t}$} & \multirow[t]{2}{*}{ Sig } & \multicolumn{2}{|c|}{ Mean \pm SD } & \multirow[t]{2}{*}{$\mathbf{t}$} & \multirow{2}{*}{$\begin{array}{l}\text { Signifi } \\
\text { cance }\end{array}$} \\
\hline & Males & Females & & & + & - & & \\
\hline $\begin{array}{l}\text { Functional } \\
\text { limitation }\end{array}$ & $1.46 \pm 1.66$ & $2.25 \pm 2.00$ & -3.180 & 0.002 & $1.79 \pm 1.84$ & $1.90 \pm 1.90$ & 0.407 & 0.685 \\
\hline $\begin{array}{l}\text { Physical } \\
\text { discomfort }\end{array}$ & $0.98 \pm 1.38$ & $1.91 \pm 2.19$ & -3.766 & 0.000 & $1.29 \pm 1.98$ & $1.53 \pm 1.83$ & 0.896 & 0.371 \\
\hline Physical pain & $2.43 \pm 2.03$ & $3.03 \pm 1.92$ & -2.239 & 0.026 & $2.71 \pm 2.13$ & $2.75 \pm 1.93$ & 0.132 & 0.895 \\
\hline $\begin{array}{l}\text { Physical } \\
\text { disability }\end{array}$ & $1.5 \pm 1.94$ & $2.39 \pm 2.08$ & -3.267 & $\overline{0.000}$ & $2.03 \pm 2.24$ & $1.90 \pm 1.95$ & -0.473 & 0.636 \\
\hline $\begin{array}{c}\text { Psychological } \\
\text { disability }\end{array}$ & $0.75 \pm 1.23$ & $1.46 \pm 1.88$ & -3.297 & 0.001 & $1.09 \pm 1.95$ & $1.12 \pm 1.67$ & 0.128 & 0.898 \\
\hline Social disability & $0.57 \pm 0.99$ & $1.56 \pm 1.98$ & -4.640 & 0.000 & $0.76 \pm 1.37$ & $1.24 \pm 1.76$ & 2.201 & 0.029 \\
\hline Handicap & $0.55 \pm 1.13$ & $1.48 \pm 1.92$ & -4.344 & 0.000 & $0.63 \pm 1.19$ & $1.23 \pm 1.81$ & 2.924 & 0.004 \\
\hline
\end{tabular}


Assessing impact of oral diseases on oral health related quality of life of institutionalized elderly

\begin{tabular}{|c|c|c|c|c|c|}
\hline Domains & Number of teeth & Mean & Std. Deviation & $\mathrm{F}$ & Significance \\
\hline \multirow{4}{*}{ Functional limitation } & No teeth & 2.40 & 2.13 & \multirow{4}{*}{5.400} & \multirow{4}{*}{0.001} \\
\hline & $<19$ & 2.09 & 2.05 & & \\
\hline & $20-23$ & 2.14 & 1.64 & & \\
\hline & $>23$ & 1.18 & 1.35 & & \\
\hline \multirow{4}{*}{ Physical pain } & No teeth & 2.77 & 2.20 & \multirow{4}{*}{1.045} & \multirow{4}{*}{0.373} \\
\hline & $<19$ & 3.04 & 1.86 & & \\
\hline & $20-23$ & 2.85 & 1.81 & & \\
\hline & $>23$ & 2.38 & 2.01 & & \\
\hline \multirow{4}{*}{$\begin{array}{l}\text { Physical } \\
\text { Discomfort }\end{array}$} & No teeth & 1.70 & 2.03 & \multirow{4}{*}{1.285} & \multirow{4}{*}{0.280} \\
\hline & $<19$ & 1.45 & 1.85 & & \\
\hline & $20-23$ & 1.71 & 2.08 & & \\
\hline & $>23$ & 1.16 & 1.72 & & \\
\hline \multirow{4}{*}{$\begin{array}{l}\text { Physical } \\
\text { Discomfort }\end{array}$} & No teeth & 2.24 & 2.28 & \multirow{4}{*}{3.443} & \multirow{4}{*}{0.018} \\
\hline & $<19$ & 2.37 & 2.17 & & \\
\hline & $20-23$ & 1.96 & 1.91 & & \\
\hline & $>23$ & 1.34 & 1.69 & & \\
\hline \multirow{4}{*}{$\begin{array}{l}\text { Psychological } \\
\text { Disability }\end{array}$} & No teeth & 1.38 & 1.85 & \multirow{4}{*}{1.288} & \multirow{4}{*}{0.279} \\
\hline & $<19$ & 1.12 & 1.67 & & \\
\hline & $20-23$ & 1.25 & 1.75 & & \\
\hline & $>23$ & 0.83 & 1.34 & & \\
\hline \multirow{4}{*}{$\begin{array}{c}\text { Social } \\
\text { Disability }\end{array}$} & No teeth & 1.38 & 1.85 & \multirow{4}{*}{1.391} & \multirow{4}{*}{0.247} \\
\hline & $<19$ & 1.12 & 1.61 & & \\
\hline & $20-23$ & 1.07 & 1.69 & & \\
\hline & $>23$ & 0.79 & 1.46 & & \\
\hline \multirow{4}{*}{ Handicap } & No teeth & 1.24 & 1.77 & \multirow{4}{*}{0.829} & \multirow{4}{*}{0.479} \\
\hline & $<19$ & 1.09 & 1.79 & & \\
\hline & $20-23$ & 1.03 & 1.47 & & \\
\hline & $>23$ & 0.79 & 1.45 & & \\
\hline
\end{tabular}

Table 6: Domain wise comparison of mean scores according to number of teeth

Figure 1 Gender difference in impact of oral diseases on the quality of life.

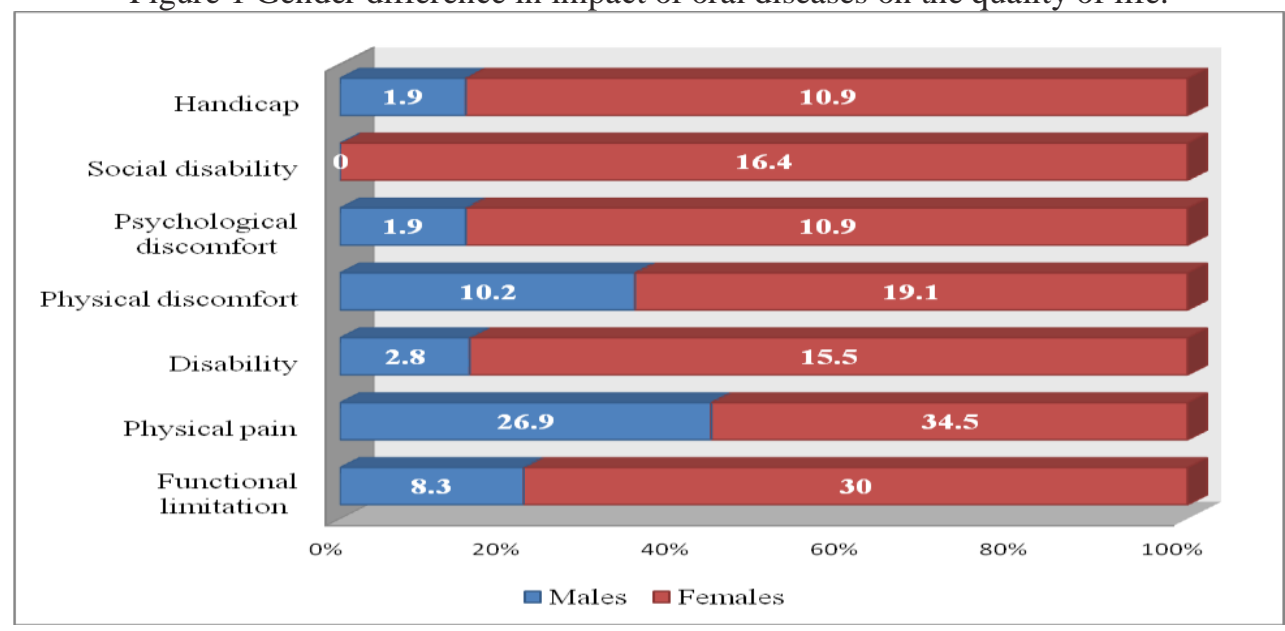


Figure 2. The impact of oral diseases on the 7 domains of OHIP-14.

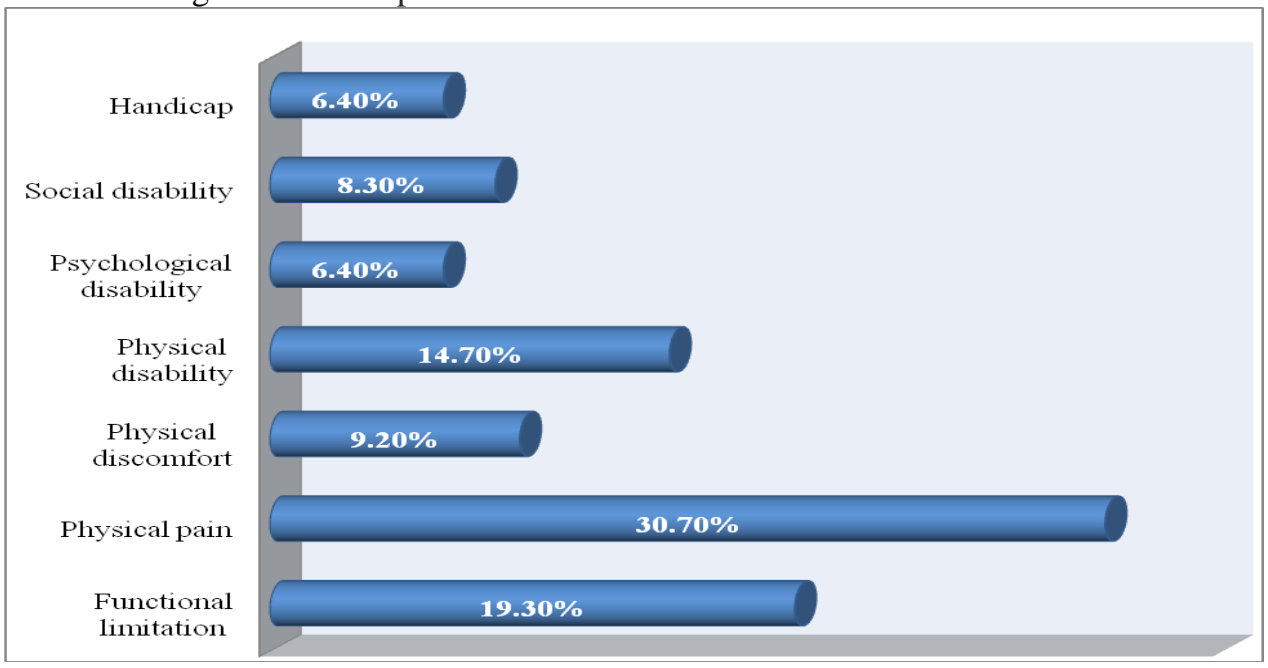

\section{Discussion}

Institutionalized and homebound elderly are found to have poorer oral health status than active elderly. It has also been repeatedly reported in the literature that the institutionalized elderly have limited access to dental care and frequently have untreated oral diseases that may have a serious impact on their quality of life $([10,11])$. Data regarding the oral health status of older people is particularly scarce from developing countries including India ([5]). Thus, there is greater emphasis on strengthening research into the oral health of older people in order to strategize programmes targeting them. As per the literature, this is the first study assessing the impact of oral diseases on the quality of lives among the institutionalized elderly people in Bengaluru.

Edentulism was the most significant problem among institutionalized elderly subjects in our study and this has been reported previously in the literature ([5]). Though the prevalence of complete edentulism reported in this study $(20.6 \%)$ is similar to the prevalence of edentulism among elderly in India according to the WHO Oral Health Data Bank (19\%), the prevalence of partial edentulism (73.4\%) among the study subjects was significantly higher. Also, this is significantly higher than the prevalence of edentulism in other Asian countries like China ([12]). Edentulism was found to be more common among females and this was similar to the results of a study conducted among retirement age people in Latvia ([13]). This could be due to the fact that in addition to low education and awareness regarding oral health, more women were unemployed and financially dependent leading to limited access to dental care.

In spite of the fact that majority of the subjects used tooth brush and tooth paste for oral hygiene maintenance, periodontal status of the elderly was poor. The prevalence of loss of attachment in this study is comparable to that of previous reports in literature ([14]). Dental caries was found only in a relatively smaller proportion of subjects in this study and this could be due to the greater proportion of edentulism seen among them. It could also be attributed to the fact that many institutions provided diet restricted in sugar and salt considering the systemic health of their inmates. Also, majority of them used fluoridated tooth pastes, though the frequency of cleaning was mostly once a day. Most of this was coronal caries with root caries in less than $5 \%$ of the subjects. This is in contrast to the general trend among elderly subjects worldwide, but in a previous Indian study, among the $12 \%$ of elderly subjects who had exposed root surfaces, none had root surface caries $([15,16])$.

Several reports worldwide have shown that use of professional dental health services is low among older people, particularly among the socio-economically disadvantaged ([17]). Dental utilization rates are lower for older adults than for younger age groups, and barriers to care have been reported to be cost of dental care, the lack of perceived need for care, transportation problems, and fear ([18]).

The impact of oral diseases on the quality of life in the study subjects as assessed by the total OHIP score $(11.9 \pm 6.5)$ is low especially considering the significant burden of oral diseases they suffer from. This is lower than the impact reported in a previous study from Chennai among adult population who visited the institution for treatment (15.5 \pm 9.6$)$. However, their study population was not confined to geriatric subjects and the very fact that they utilized the services reflected their increased awareness ([19]). Though dental diseases like caries and periodontitis did not cause a significant impact on the domains, it was found that the consequences of the diseases like grossly destructed teeth and edentulism impacted their daily life activities. It was found that having less number of teeth creates significant impact in the functional limitation and physical discomfort domains of quality of life. This finding corroborates with the results of a systematic review and 
meta-analysis which provides fairly strong evidence that the number and location of tooth loss affects the severity of impairment of quality of life of individuals ([20]).

The impact of oral diseases on the institutionalized elderly was relatively higher in previous studies using OHIP scale ([21]). However, a study comparing the impact of oral diseases among institutionalized and non-institutionalized elderly in Hong Kong found that there was no statistically significant difference between the two groups ([11]). This reduced impact on the elderly subjects in this study has to be analyzed considering the unique social, economic, and cultural environment of the population. Oral diseases are not perceived as life threatening or serious by majority of Indians and hence oral health is generally given a low priority. ${ }^{22}$ This fact compounded by the low awareness and socio economic status of the study subjects could be responsible for the low perceived impact.

Females experienced greater impact of oral diseases than males in all the domains of OHIP and this is corroborating with the findings from a previous study conducted in Brazil ([9]). When individual domains are considered the difference in the attitude between the genders becomes more obvious (Figure: 2). Greater proportion of males $(26.9 \%)$ and females $(34.5 \%)$ had significant impact on the domain of physical pain. But, in psycho social domains like psychological discomfort (1.9\%) and handicap (1.9\%), a very small proportion of males experienced an impact. None of the male subjects experienced an impact in the social disability domain. However, greater proportion of females experienced impact in the psychological disability (10.9\%), social disability $(16.4 \%)$ and handicap $(10.9 \%)$ domains. These results indicate that while oral diseases are perceived as physical experiences by the males, they are also psychosocial experiences for the females.

Another significant finding is the impact that reduced utilization has on the social disability and handicap domains of the subjects. Older adults are maintaining their natural teeth into their later years, and epidemiologic trends suggest the increasing need for dental services by older adults. Yet dental utilization rates are lower for older adults than for younger age groups, and barriers to care include the cost of dental care, the lack of perceived need for care, transportation problems, and fear. Oral diseases and impairments are most commonly experienced by those segments of society least able to obtain dental care. Economically and socially disadvantaged older adults and the physically impaired are more likely to experience tooth loss and edentulism, untreated dental decay and periodontal diseases. ${ }^{18}$ One major limitation of this study is that the socio dental indicator OHIP-14 was not cross culturally adapted and validated for the target population. The validity of the subjective outcomes could have been compromised due to this issue. However, the interviewers were well trained and calibrated and were proficient in the local language.

\section{Conclusion}

Based on the results of this study, it can be concluded that oral health status of the institutionalized geriatric population of Bengaluru, India is poor, with edentulism, periodontitis and under utilization being major concerns. The impact of oral diseases on the lives of elderly is relatively lower and disproportionate compared to the disease burden among the subjects. This strongly emphasizes the low value placed on oral health and low awareness regarding oral diseases. There is a need to develop culturally sensitive socio dental indicators suitable to assess subjective outcomes of the Indian population.

\section{Recommendations}

Oral disease burden mandates the need for specialized oral health promotion programmes targeting the geriatric population, particularly the institutionalized and home bound, in order to improve their oral health. Adequacy of current academic program in providing training regarding the behavioral dimensions and multi disciplinary approach needed to manage elderly patients should be evaluated in further research. Finally, considering the low socio economic status of the dependent elderly, providing them with low cost dental treatment at public and private oral health care facilities should also be considered.

\section{References}

[1]. World Population Prospects: The 2002 Revision, United Nations Population Division New York, NY, USA: United Nations; 2003(Cited 2005 Feb 24). Available from: URL: http://www.un.org/esa/population/publications/wpp2002/WPP2002HIGHLIGHTSrev1.PDF

[2]. Active ageing: a policy framework. World Health Organization. Geneva, Switzerland 2000. Available from: URL: http://whqlibdoc.who.int/hq/2002/who_nmh_nph_02.8.pdf

[3]. Walls AWG, Steele JG, Sheiham A, Marcenes W, Moynihan PJ. Oral health and nutrition in older people. J Public Health Dent 2000;60:304-7.

[4]. Joshipura KJ, Hung H-C, Rimm EB, Willett WC, Ascherio A. Periodontal disease, tooth loss, and incidence of ischemic stroke. Stroke 2003;34:47-52.

[5]. Petersen PE, Yamamoto T. Improving the oral health of older people: the approach of the WHO Global Oral Health Programme. Community Dent Oral Epidemiol 2005;33:81-92.

[6]. Shah N. Speaking for myself. The National Medical Journal Of India 2005; 18(1): 37-38.

[7]. Slade GD. Derivation and validation of a short-form Oral Health Impact Profile. Community Dent Oral Epidemiol 1997;25:284-90.

[8]. Oral Health Survey Basic methods 4th ed. World Health Organization Geneva, Switzerland 1997. Available from: URL: http://www2.paho.org/hq/dmdocuments/2009/OH_st_Esurv.pdf 
[9]. Araújo ACS, Gusmão ES, Batista JEM, Cimões R. Impact of periodontal disease on quality of life. Quintessence Int 2010;41(6):111-18.

[10]. Pajukoski H, Meurman JH, Snellman-Grohn S, Sulkava R. Oral health in hospitalized and nonhospitalized community-dwelling elderly patients. Oral Surg Oral Med Oral Pathol Oral Radiol Endod 1999;88:437-43.

[11]. Mcmillan AS, Wong MCM, Lo ECM, Allen PF. The impact of oral disease among the institutionalized and non-institutionalized elderly in Hong Kong. Journal of Oral Rehab 2003;30:46-54

[12]. Hu D, Hong X, Li X. Oral health in China - trends and challenges. Int J Oral Sci 2011; 3: 7-12.

[13]. Vidzis A, Cema I, Krasta I, Brinkmane A, Kalnins I. Evaluation of oral health status of retirement-age population in Latvia. Stomatologija Baltic Dental and Maxillofacial Journal 2011;13:68-72.

[14]. Zahrani AA. Dental health status in a sample of elderly patients in Riyadh, Saudi Arabia. Saudi Dental Journal 2005 May;17(2):7482.

[15]. Schou L. Oral health, oral health care, and oral health promotion among older adults: social and behavioral dimensions. In: Cohen LK, Gift HC, editors. Disease Prevention and Oral Health Promotion. Copenhagen: Munksgaard;1995.

[16]. Thomas S, Raja RV, Kutty R, Strayer MS. Pattern of caries experience among an elderly population in South India. Int Dent J 1994;44:617-622.

[17]. Petersen PE, Holst D. Utilization of dental health services. In: Cohen L, Gift HC, editors. Disease Prevention and Oral Health Promotion. Copenhagen: Munksgaard;1995

[18]. Dolan TA, Atchison KA. Implications of access, utilization and need for oral health care by the non-institutionalized and institutionalized elderly on the dental delivery system. J Dent Educ 1993 Dec;57(12):876-87.

[19]. Ingle NA, Chaly PE, Zohara CK. Oral health related quality of life in adult population attending the outpatient department of a hospital in Chennai, India. J Int Oral Health 2010;2(4):45-56.

[20]. Gerritsen AE, Allen P, WitterDJ, Bronkhorst EM, Creugers NHJ. Tooth loss and oral health-related quality of life: a systematic review and meta-analysis. Health and Quality of Life Outcomes 2010;8:126.

[21]. Slade GD, Spencer AJ. Social impact of oral conditions among older adults. Aust Dent J 1994;39:358-364.

[22]. Prakash H, Shah N. National Oral Health Care Programme: Implementation Strategies. New Delhi: National Oral Health Care Programme, Govt. of India; 2001. 